\title{
A Case of Treatment Resistant Depression Who Did Not Respond to ECT (Electroconvulsive Therapy) and Responded to rTMS (Repetitive Transcranial Magnetic Stimulation)
}

\author{
Georgios Mikellides* and Marianna Tantele \\ honorary Assistant Professor University of Nicosia, Cyprus \\ Received: 阱 August 08, 2018; Published: 眥 August 14, 2018 \\ *Corresponding author: Georgios Mikellides, honorary Assistant Professor University of Nicosia, Consultant Psychiatrist at Cyprus \\ rTMS
}

\section{Introduction}

The use of repetitive transcranial magnetic stimulation has grown over the last ten years since the FDA approval in 2008 and has been also included in NICE UK as an optional treatment [1] and it is likely to continue to grow in terms of its use as it has been showing the following promising findings: good results in a variety of neuropsychiatric disorders such as anxiety [2], obsessive compulsive disorder [3], auditory hallucinations [4], PTSD [5], tinnitus [6], migraine [7], post-stroke rehabilitation [8] etc. It also provides a neuroprotective mechanism [9] which may enhance cognitive function.

\section{A Case Study}

We would like to present a 52 year old lady with a history of recurrent depressive disorder, with the current episode lasting over two years. She had a history of recurrent depressive disorder since she was 17 years old. Her current presentation was with decreased sleep, decreased appetite, lack of concentration, lack of energy, low mood and anhedonia as she could not enjoy anything in her life anymore. She was partially functioning socially and with keeping up a part time job. She was on Lamictal (Lamotrigine) $50 \mathrm{mg} \mathrm{BD}$, Efexor XR (Venlafaxine) 150mg daily, Seroquel (Quetiapine) 50mg nocte and Wellbultrin (Buproprion) 150mg daily when she came to our clinic. She was previously tried on higher doses of Efexor XR (Venlafaxine) with no response from her clinical history.

Also 6 months prior to attending to our clinic she received a total of 8 sessions of ECT twice weekly with some improvement in her mental state at the time but not with a sustainable effect and did not lead to a full recovery. She had a medication review and Lamotrigine was stopped to have a better effect with rTMS. Subsequently we did start a 5 times per week rTMS course over 6 weeks with a magpro (Magventure) stimulator, theta burst pulses were given for 3 minutes in each session, on the left DLPFC, a total of thirty sessions. The patient went into a full recovery of her depressive episode one week post treatment completion. We also stopped Buproprion, Quetiapine and during treatment we also increase Venlafaxine XR to $150 \mathrm{mg}$ BD. She did not present with any side effects from the rTMS therapy. She was also reviewed a month post treatment and the effect was sustained and decided to have a monthly maintenance session with rTMS.

\section{Conclusion}

Our case suggests that rTMS can be an effective treatment option in treatment resistant depression even in patients that they have been previously tried on ECT and did not recover or sufficiently responded. Also, the recommendation could be that rTMS could be used as a first line treatment in patients with depression as it presents with less side effects as if its to be compared to medications or ECT and its an effective and safe treatment above all.

\section{References}

1. NICE (2015) Repetitive transcranial magnetic stimulation for depression.

2. Trevizol AP, Shiozawa P, Sato IA (2016) Transcranial magnetic stimulation for anxiety symptoms: an updated systematic review and meta-analysis. Abnorm Behav Psychol 2(1).

3. Berlim MT, Neufeld NH, Van den Eynde F (2013) Repetitive transcranial magnetic stimulation (rTMS) for obsessive-compulsive disorder (OCD): an exploratory meta-analysis of randomized and sham-controlled trails. J Psychiatr Res 47(8): 999-1006.

4. Dollfus S, Lecardeur L, Morello R, Etard O (2016) Placebo response in repetitive transcranial magnetic stimulation trials of treatment of auditory hallucinations in schizophrenia: a meta-analysis. Schizophr Bull 42(2): 301-308.

5. Rosenberg PB, Mehndiratta RB, Mehndiratta YP, Wamer A, Rosse RB, et al. (2002) Repetitive transcranial stimulation treatment of comorbid 
post-traumatic stress disorder and major depression. J Neuropsych Clin Neurosci 14(3): 270-276.

6. Soleimani R, Jalali M, Hasandokht $T$ (2016) Therapeutic impact of repetitive transcranial magnetic stimulation (rTMS) on tinnitus: a systematic review and meta-analysis. Eur Arch Otorhinolaryngol 273(7): 1663-1675.

7. NICE (2014) Transcranial Magnetic Stimulation for treating and preventing migraine.

\section{ISSN: 2574-1241}

DOI: $10.26717 /$ BJSTR.2018.08.001582

Georgios Mikellides. Biomed J Sci \& Tech Res

This work is licensed under Creative

Commons Attribution 4.0 License

Submission Link: https://biomedres.us/submit-manuscript.php
8. Barwood CHS, Murdoch BE, Whelan BM, Lloyd D, Riek S, et al. (2011) Improved language performance subsequent to low-frequency rTMS in patients with chronic non-fluent aphasia post-stroke. Eur J Neurol 18(7): 935-943.

9. Fei Wang, Guang-ming Chang, Qian Yu (2015) The Neuroprotection of Repetitive Transcranial Magnetic Stimulation Pre-treatment in Vascular Dementia Rats. J Mol Neurosci 56(1): 198-204.

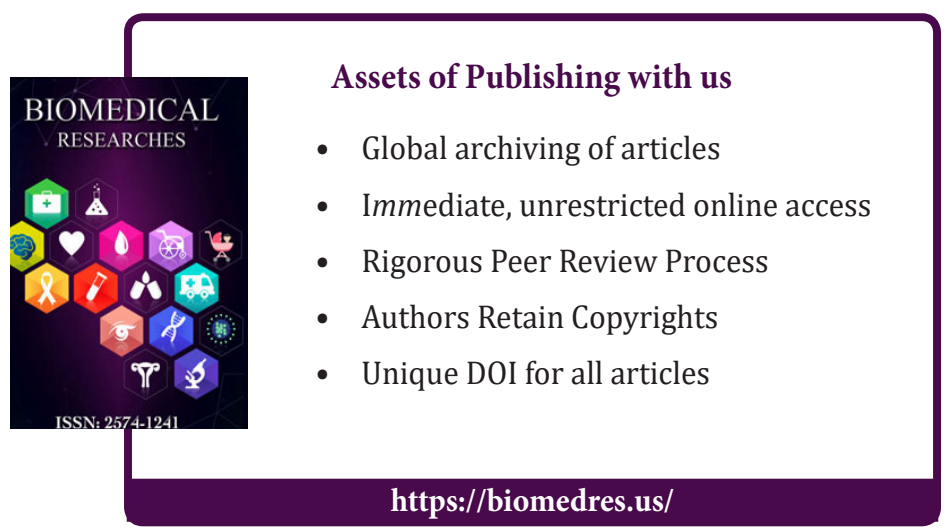

